\title{
Water regeneration as an economical advantage of contemporary pasteurizing machines
}

\author{
Vasilii Kazmin, Sergei Kudryashev*, Georgy Kazmin, Viktor Naumenko \\ Don State Technical University, Automation department, 344000 Rostov-on-Don, Russia
}

\begin{abstract}
Annotation. The problem of preserving food and increasing their biological stability is one of the important problems of modern food production. The pasteurization process, due to the transition to a temperature of up to 60-70 degrees, remains unchanged preservation of liquid products. The considered system of the tunnel pasteurization process, which is used in the production of beer and other fermentation beverages, makes it possible to increase the energy efficiency of the pasteurization process due to the reuse of heated water and temperature exchange between the chambers of the system and product cooling. Reducing energy consumption for heating by using such an automated system can be up to five times. In addition, the use of this system leads to significant savings in water consumption.
\end{abstract}

\section{Introduction}

One of the most effective ways to extend the shelf life of liquid food products is pasteurization. Pasteurization was developed by Louis Pasteur in 1864 as a method of fighting wine diseases by heating drinks at temperatures between 50 and 60 degrees

The process of pasteurization of a drink is accepted to be divided into three main types:

1. Hot filling

2. Brief heating before filling

3. Complete pasteurization in a tunnel pasteurizer

It is impossible to destroy all microorganisms by pasteurization even at high temperatures (below boiling point), while it is necessary to maintain a balance between the destruction of harmful microorganisms and the preservation of the rest, which determine the taste and useful properties of the product [3-6].

Thus, with the help of the system of the fastest possible soft and smooth operation for all healthy drinks.

In the process of pasteurization, two important resources are used - water and energy, the careful use of which has been and is used by the well-known application of modern production. The use of energy and resource-saving production today is not only an economic issue.

* Corresponding author: skudryshov@donstu.ru 


\section{Materials and methods}

The research and calculations of the energy cost decreasing were based on the materials, attached to the new pasteurizing machine, as an operator manual and other necessary for customer stuff. The basis of recuperation principle was tested on some brew plants in Russia [1, 2, 5].

\section{Results}

\subsection{Necessary heat temperature determination}

It is possible to increase the biological stability, provided that the drink is free from yeast and other microorganisms by various filtration methods, or their activity should be limited so that the quality of the drink is preserved during storage.

To prolong the biological resistance, apply:

1. pasteurization of the spilled beverage in the package;

2. flow pasteurization and filling under aseptic conditions;

3. hot filling of the drink into the package;

4. release of the drink from microorganisms by filtration and filling under aseptic conditions.

Pasteurization of packaged food drinks, such as beer, is the most common way to store them for longer. The killing effect of microorganisms when the temperature rises can be increased in pasteurization units (PU - (pasteurization unit)). Conditional calculated value, the achievement of which is necessary for the correct pasteurization of the drink. The pasteurization unit is considered to be the effect of killing microorganisms in 1 minute at a temperature of 60 degrees Celsius.

where:

$$
\text { P.U. }(t, T)=t * 1.389^{\left(T-60^{\circ} C\right)}
$$

$t$ - time (minutes)

$T$ - temperature (Celsius degrees)

1.389 - calculated constant value for beer. This value is always different for each kind of liquid.

\subsection{Cost effective application of tunnel pasteurizers}

1) The first step is heating the product.

2) The second step is heating and pasteurization.

3) The third step is cooling.

Let's consider a real-life example. By transport conveyors, products (drinks in cans) are delivered to the inlet of the pasteurizer. The average temperature of the cans is 4 degrees Celsius. In this case, the required pasteurization temperature calculated by the laboratory is 70 degrees. Thus, it is necessary to smoothly heat the product to the specified limits. Plus, a sharp temperature drop is an unacceptable number of problems, such as, for example, a can explosion. The next step is to smoothly cool the drink to an average temperature of 30 degrees Celsius. The reason for that will be considered below. 


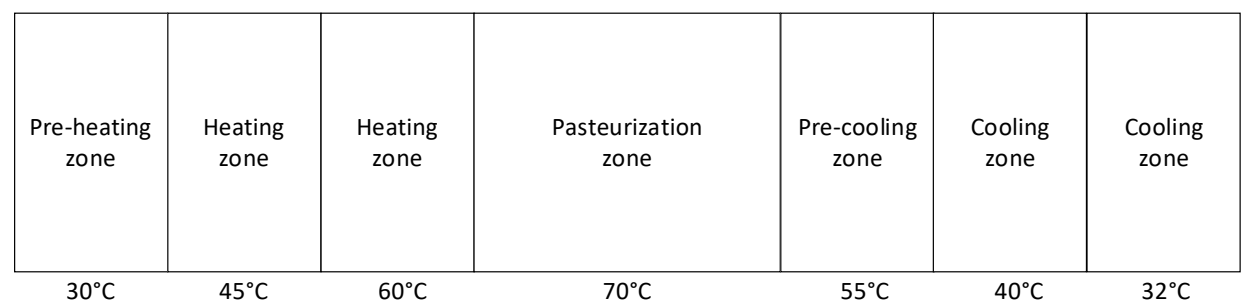

Fig. 1. Pasteurizator's temperature zones

\subsection{Water and heat recovery}

The process of cooling the product before leaving the pasteurizer is important for economic reasons. This allows you to significantly reduce the consumption of electricity for heating the machine, as well as reduce water consumption.

At the moment the entered can is in the pasteurizing degree, it gradually increases due to contact with warm water sprinkling from the nozzles inside a particular section. The flowing water goes into a special tank, where it is accumulated for further use. The temperature of this water is about 20 degrees. The next step through a special system of pipes and pumps, this water is directed to the extreme pre-cooling section of the product. The main system controller automatically regulates this flow of hot water as needed to operate the outlet temperature.

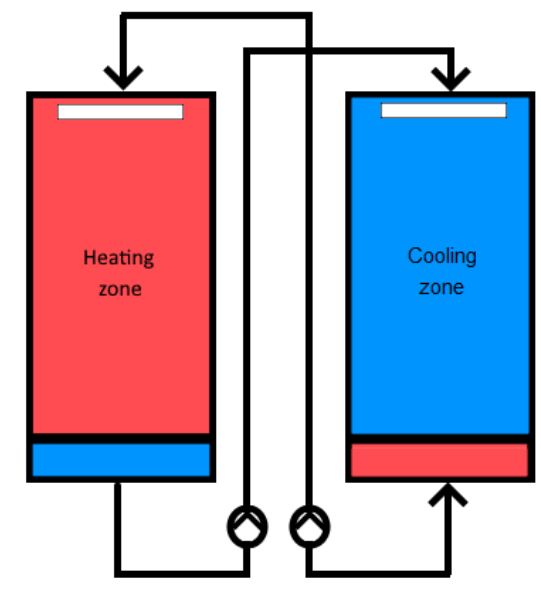

Fig. 2. Heating and cooling zone's connections

Similarly, the water formed in the lower tanker of the penultimate cooling zone, being warmer due to contact with a warm can, is directed to the first preheating zone, and is mixed depending on the conditions with warm water. The temperature is about 30 degrees. This cycle runs continuously while the machine is operating.

Likewise, depending on the configuration of the equipment, as well as the manufacturer, temperature exchanges are formed between other sections of cooling and heating products.

It should be understood that the two main zones of the machine work differently, without having a regeneration system with other sections.

The pasteurization zone has its own closed loop of hot water, passing directly through heat exchangers, which, in turn, are heated by steam passing through them. Various temperature sensors allow precise control of the current temperature inside the 
pasteurization zone, and the controller automatically regulates the supply of hot water through automatic control valves. If the temperature is too high inside this zone, then the cold water supply valve opens.

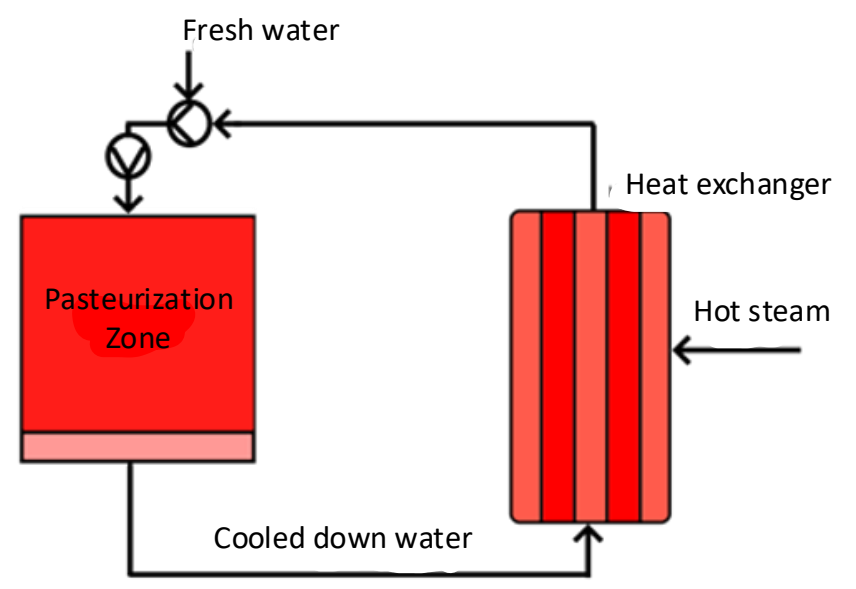

Fig. 3. Heat recovery between pasteurization zone and heat exchanger

The cooling zone also has its own closed cold-water circuit. To maintain the temperature within the specified limits, the water taken from the collection tanker passes through an external cooling station.

Calculation of the required temperature for heating 1 ton of water per 1 degree Celsius.

That's necessary to assume that all the water used goes down the drain.

What energy consumption would be expected:

The formula for calculating the amount of energy required to heat 1 liter of water per 1 degree Celsius:

where:

$$
Q=C * m
$$

$\mathrm{C}$ - specific heat, i.e. the energy required to heat a substance by 1 degree. For water at normal pressure $(101.325 \mathrm{kPa})$, this is 4200 joules.

$\mathrm{m}$ - mass, 1 liter of water under normal conditions has a mass of $1 \mathrm{~kg}$.

It is not possible to obtain accurate information about the water consumption in each section of the pasteurizer due to the confidentiality of the calculation data. Therefore, we will take approximate figures and, based on their example, calculate the energy savings due to the use of temperature regeneration technology.

Let the cold water in the pipes have a temperature of 10 degrees Celsius.

For 1 minute of operation, 250 liters of water are passed through the nozzles of the first section. Thus, we can calculate the amount of energy expended:

where:

$$
\mathrm{Q}=\mathrm{C} * \mathrm{~m} *\left(\mathrm{t}_{2}-\mathrm{t}_{1}\right)
$$

$t_{2}$ - upper heating temperature.

$t_{1}$ - initial temperature.

Result:

For 1 hour we need energy:

$$
Q=4200 * 250 *(30-10)=21,000,000 \mathrm{~J}=350 \mathrm{kWt} .
$$

$$
Q=350 * 60=21000 \mathrm{kWt} * h .
$$

Calculation of the energy amount required to heat water to the desired temperature when using temperature regeneration with a ratio of incoming secondary water with the already required temperature of $80 \%$ and added fresh water $20 \%$ : 
Result:

$$
Q=C * m *\left(t_{2}-t_{1}\right)
$$

$$
Q=4200 * 250 * 0.2 *(30-10)=4,200,0000 \mathrm{~J}=70 \mathrm{kWt} .
$$

For 1 hour we need energy:

$$
Q=70 * 60=4200 \mathrm{kWt} * h .
$$

Thus, we get a 5 -fold reduction in energy consumption for water heating.

The rest of the sections have a similar correlation, differing in such indicators as the ratio of mixed regeneration and fresh waters, the initial temperature of these waters and required in a particular section.

Let's calculate the approximate water savings for these parameters.

Consumption without water regeneration:

$$
P=250 * 60=15000 l
$$

Consumption with water regeneration:

$$
P=250 * 0.2 * 60=3000 l .
$$

Total: saving 12 tons of water per hour due to the use of water regeneration.

In this case, it makes no sense to calculate the total energy and water savings due to the fact that there are many variations of machines, each has a different number of sections, their length, number of floors, etc.

\section{Conclusion}

Thus, we can say with complete confidence that modern pasteurizers are energyefficient automation technologies. Using water regeneration technology within the system, these machines effectively transfer heat between sections, what helps to dramatically reduce energy consumption. Apart from this, control of water consumption is also a huge advantage of pasteurizers. In modern conditions of special attention to ecology and the environment, pasteurizers are used as efficiently and safely as possible for nature.

\section{References}

1. R.D. Belashov, N.S. Aseev, S.B. Kudryashov, Actual problems of science and technology (2020)

2. R.D. Belashov, N.S. Aseev, S.B. Kudryashov, V. A. Naumenko, Real-time control of the density of products at various stages of the sugar production process. XIII International Scientific and Practical Conference, (2020)

3. R. Simpson, Engineering Aspects of Thermal Food Processing (2009)

4. M. Karel, D. B. Lund, Physical Principles of Food Preservation (2003)

5. E. Mironova, E. Romanenko, M. Selivanova, T. Aysanov, M. German E3S Web Conf. 244, (2021) https://doi.org/10.1051/e3sconf/202124402004

6. W. Kunze, Technology brewing and malting (2014)

7. V.A. Panfilov, Machines and apparatus for food production (2007)

8. S. K. Das, M. Das, Fundamentals and Operations in Food Process Engineering (2019)

9. M. J. Lewis, N. J. Heppell, Continuous Thermal Processing of Foods: Pasteurization and UHT Sterilization (Food Engineering Series) (2000)

10. F. Glavcheck, A. Lhotskii, Brewing (1977) 